\title{
A SISCAPA-based approach for detection of SARS-CoV-2 viral antigens from clinical samples
}

\author{
Kiran K. Mangalaparthi ${ }^{1 \dagger}$, Sandip Chavan ${ }^{1 \dagger}$, Anil K. Madugundu 1,2,3,4, Santosh Renuse ${ }^{1,5}$, \\ Patrick M. Vanderboom ', Anthony D. Maus', Jennifer Kemp' ${ }^{1}$, Benjamin R. Kipp ${ }^{6}$, Stefan K. Grebe ${ }^{1,7}$, \\ Ravinder J. Singh ${ }^{1}$ and Akhilesh Pandey ${ }^{1,45^{*}}$ (D)
}

\begin{abstract}
SARS-CoV-2, a novel human coronavirus, has created a global disease burden infecting $>100$ million humans in just over a year. RT-PCR is currently the predominant method of diagnosing this viral infection although a variety of tests to detect viral antigens have also been developed. In this study, we adopted a SISCAPA-based enrichment approach using anti-peptide antibodies generated against peptides from the nucleocapsid protein of SARS-CoV-2. We developed a targeted workflow in which nasopharyngeal swab samples were digested followed by enrichment of viral peptides using the anti-peptide antibodies and targeted parallel reaction monitoring (PRM) analysis using a high-resolution mass spectrometer. This workflow was applied to 41 RT-PCR-confirmed clinical SARS-CoV-2 positive nasopharyngeal swab samples and 30 negative samples. The workflow employed was highly specific as none of the target peptides were detected in negative samples. Further, the detected peptides showed a positive correlation with the viral loads as measured by RT-PCR Ct values. The SISCAPA-based platform described in the current study can serve as an alternative method for SARS-CoV-2 viral detection and can also be applied for detecting other microbial pathogens directly from clinical samples.
\end{abstract}

Keywords: SARS-CoV-2, COVID-19, SISCAPA, Mass spectrometry, Parallel reaction monitoring (PRM)

\section{Introduction}

The coronavirus outbreak that started at the end of 2019 has become a major challenge to the health system worldwide [1]. The transmission of the SARS-CoV-2 virus from human-to-human is very high necessitating early and accurate diagnosis of the infected individuals for disease control. Reverse transcriptase-polymerase chain reaction (RT-PCR) has been the gold standard testing method for the detection of SARS-CoV-2. Several other methods

\footnotetext{
*Correspondence: pandey.akhilesh@mayo.edu

† Kiran K. Mangalaparthi and Sandip Chavan are first authors

${ }^{1}$ Department of Laboratory Medicine and Pathology, Division of Clinical Biochemistry and Immunology, Mayo Clinic, Rochester, MN 55905, USA

Full list of author information is available at the end of the article
}

have been developed for the diagnosis of COVID-19 which are based on the detection of viral proteins, antiviral antibodies or nucleic acids [2]. Owing to increasing number of infections worldwide, alternate screening methodologies need to be explored especially in light of logistical issues pertaining to reagents and instruments for RT-PCR-based tests [3, 4].

Mass spectrometry is an excellent analytical tool that can be applied for analysis of a diverse array of analytes such as small molecules, proteins and peptides [5]. Targeted analysis using multiple reaction monitoring (MRM) or parallel reaction monitoring (PRM) has become a feasible alternative to immunoassays [6]. Automation for sample preparation and data analysis has further helped in increasing original author(s) and the source, provide a link to the Creative Commons licence, and indicate if changes were made. The images or other third party material in this article are included in the article's Creative Commons licence, unless indicated otherwise in a credit line to the material. If material is not included in the article's Creative Commons licence and your intended use is not permitted by statutory regulation or exceeds the permitted use, you will need to obtain permission directly from the copyright holder. To view a copy of this licence, visit http://creativecommons.org/licenses/by/4.0/. The Creative Commons Public Domain Dedication waiver (http://creativeco mmons.org/publicdomain/zero/1.0/) applies to the data made available in this article, unless otherwise stated in a credit line to the data. 
the specificity and throughput. Several groups have attempted to automate the chromatographic conditions and analysis workflow for the detection of SARS-CoV-2 using mass spectrometry. Cardozo, et al. used turbulent flow chromatography coupled to tandem mass spectrometry, which enabled analysis of samples with increased throughput and demonstrated a sensitivity of $78 \%$ [7]. Another study used a MALDI-MS approach for the diagnosis of the SARS-CoV-2 based on the distinct spectral features in COVID-19 patients selected by machine learning approaches, however, the chemical identity of the spectral features remains unknown [8]. There are several other published studies which describe detection of viral antigen from clinical specimens based on targeted proteomics [9-13]. Notably, Renuse et al. employed nucleocapsid protein enrichment followed by LC-FAIMS-PRM approach for detection SARSCoV-2 from nasopharyngeal swab (NP swab) samples. In addition, a machine learning approach was used on fragment ion intensities to achieve a sensitivity of $98 \%$ and a specificity of $100 \%$ [14].

MRM or PRM assays are based on targeted measurement of peptides that are unique to the protein of interest. However, the sensitivity of these assays can be limited in complex matrices. Enrichment of the specific peptides by affinity purification prior to LC-MS/MS analysis improves the sensitivity and performance of the assay especially in biological fluids such as serum, plasma, cerebrospinal fluid, urine, and whole blood, which are commonly used in clinical laboratories. Stable Isotope Standards and Capture by Anti-Peptide Antibodies (SISCAPA) workflow enables the enrichment of target peptides by employing anti-peptide antibodies [15]. SISCAPA-based target enrichment followed by targeted MS/MS analysis has been shown to yield precise and accurate quantitation of the target analytes. Several studies have used SISCAPA workflow to develop quantitative assays for proteins [16-22]. Developing the SISCAPA workflow for SARS-CoV-2 detection might provide an improvement in sensitivity, especially in clinical samples with low viral load.

In this study, we generated antibodies against viral nucleocapsid-derived peptides and developed a semiautomated yet sensitive SISCAPA-based approach for the detection of virus from nasopharyngeal swab samples from COVID-19 patients. Using this approach, we were able to successfully detect viral peptides directly from patient samples including those with low viral loads.

\section{Methods}

\section{Sample collection and handling}

Residual SARS-CoV-2 positive and negative nasopharyngeal swab samples were collected after routine diagnostic testing using RT-PCR. These samples were collected in sterile phosphate buffer saline solution and were stored at $-80{ }^{\circ} \mathrm{C}$ until further processing. All the samples were collected after prior approval from Mayo Clinic's Institutional Review Board.

\section{Selection of target peptides and peptide synthesis}

Annotated nucleocapsid protein sequences were downloaded for the SARS-CoV-2, SARS-CoV, MERS and the common human coronaviruses (OC43, HKU1, NL63 and L229E) from the NCBI. Multiple sequence alignment of downloaded nucleocapsid protein sequences was carried out using Clustal Omega at EMBL-EBI [23]. Non-synonymous coding variants identified in the SARS-CoV-2 genomes available from GISAID platform (https://www.gisaid.org/) were downloaded from the GESS database [24]. Peptides encoded in the regions of nucleocapsid protein that were mutated in $>1 \%$ of sequenced cases in GISAID were excluded. The peptide standards were purchased from New England Peptide (Gardner, MA) and were handled as per published recommendations [25].

\section{Processing of nasopharyngeal swab samples}

$750 \mu \mathrm{l}$ of each nasopharyngeal swab samples were collected in a 96-well plate. Viral inactivation and reduction of proteins was done by addition of $15 \mu \mathrm{l}$ of $1 \mathrm{M}$ dithiothreitol and $15 \mu \mathrm{l}$ of $0.1 \%$ Zwittergent 3-16 (Z-3-16) detergent (EMD Millipore, Billerica, MA, USA) and incubating at $70{ }^{\circ} \mathrm{C}$ for $30 \mathrm{~min}$. Alkylation was done using $45 \mu \mathrm{l}$ of $1 \mathrm{M}$ iodoacetamide (Sigma, St. Louis, MO, USA), vortexed and incubated in dark for $30 \mathrm{~min}$. Finally $250 \mu \mathrm{l}$ of $1 \mathrm{M}$ Tris hydrochloride solution (Sigma, St. Louis, MO, USA), pH 8.0 buffer was added and digested using $2.5 \mu \mathrm{g}$ of Worthington TPCK treated trypsin (Thermo Fisher Scientific, Waltham, MA, USA) by incubating at $37{ }^{\circ} \mathrm{C}$ for $16 \mathrm{~h}$. The reaction was stopped by adding $5 \mu \mathrm{g}$ of tosyl-Llysyl-chloromethane hydrochloride (TLCK) (Millipore Sigma, St. Louis, MO, USA) to each sample.

\section{Antibody coupling to MSIA tips and process automation}

The polyclonal anti-peptide rabbit antibodies $(1 \mu \mathrm{g})$ were conjugated to custom Mass Spectrometric Immunoassay (MSIA) Tips by Thermo Fisher Scientific (Tempe, AZ). All the samples were processed and digested as described under sample preparation section. The digested samples were then subjected to binding and elution using a Versette PlateMate 
robotic workstation (Thermo Fisher Scientific, Tempe, AZ). A total of $1 \mathrm{ml}$ of digested sample was used for the enrichment. The digest was split into three parts and peptides were then enriched separately with repeated (1000 repetitions) drawing and expelling of $300 \mu \mathrm{l}$ aliquot of sample volume through the antibody crosslinked MSIA Tips. After enrichment, target peptides were eluted in $100 \mu \mathrm{l}$ of $0.2 \%$ TFA containing $0.002 \%$ of Z3-16 detergent (Millipore Sigma, Burlington, MA). The samples were then dried and analyzed with high-resolution liquid chromatography tandem mass spectrometry (LC-MS/MS) using PRM as described below.

PRM analysis of NP swab samples processed using SISCAPA workflow

PRM analysis was performed on an Orbitrap Eclipse Tribrid Mass Spectrometer interfaced with an UltiMate 3000 RSLC nano system (Thermo Scientific, San Jose, CA). The peptides were loaded onto a trap column (PepMap $\mathrm{C}_{18} 2 \mathrm{~cm} \times 100 \mu \mathrm{m}, 100 \AA$ ) at a flow rate of $20 \mu \mathrm{l} / \mathrm{min}$ using $0.1 \%$ formic acid in water and separated on an analytical column (PepSep $10 \mathrm{~cm} \times 100 \mu \mathrm{m}, \mathrm{C}_{18} 1.9 \mu \mathrm{m}, 100 \AA$, PepSep, Marslev, Denmark) with a flow rate of $500 \mathrm{nl} / \mathrm{min}$ with a linear gradient of 5 to $40 \%$ solvent B (100\% ACN, $0.1 \%$ formic acid) over a 25 min gradient. Both precursor and fragment ions were acquired in the Orbitrap mass analyzer. Precursor ions were acquired in $\mathrm{m} / \mathrm{z}$ range of 350-1700 with a resolution of 120,000 (at $m / z 200$ ), AGC target of $3 \times 10^{4}$, maximum injection time of $200 \mathrm{~ms}$ and isolation window of $\mathrm{m} / z$ 1.6. Precursor fragmentation was carried out using higher-energy collisional dissociation method using $28 \%$ normalized collision energy. The MS/MS spectra were acquired at a resolution of $30,000($ at $m / z 200)$ in the orbitrap analyzer. The scans were arranged in top-speed method with $3 \mathrm{~s}$ cycle time between MS and MS/MS. Ion transfer capillary voltage was maintained at $2.2 \mathrm{kV}$. For internal mass calibration, lock mass option was enabled with polysiloxane ion $(m / z, 445.120025)$ from ambient air.

\section{Data analysis}

The data analysis was performed using Skyline [26]. The peaks were manually verified for correct detection of the peak, exact integration and lacking the interferences. The total peak area was calculated by summing all the selected transitions. The coefficient of variation $(\mathrm{CV})$ was calculated by dividing standard deviation with mean and expressed as a percentage.

\section{Results and discussion}

Selection of candidate peptides for the detection of SARS-CoV-2 using SISCAPA approach

The SISCAPA approach employs immunoprecipitation of peptides as surrogates for protein quantitation. Thus, selection of peptides unique to the target protein of interest is a crucial step for the development of targeted method. The nucleocapsid protein is the most abundant protein in the SARS-CoV-2 proteome ( 1000 copies/virion). Owing to its high abundance, it is being used for the development of assays using various approaches for the detection of SARS-CoV-2 virus in clinical samples. However, due to its interaction with various cellular proteins during viral replication, immunoprecipitation of nucleocapsid protein could lead to increase in the background matrix complexity and thus decrease in the sensitivity of the targeted method. Thus, enrichment of peptides from digested samples using anti-peptides antibodies could alleviate these issues increasing the sensitivity of the targeted assay.

As SARS-CoV-2 belongs to the family of coronaviruses which also include common cold viruses, peptides unique to SARS-CoV-2 were selected by performing multiple sequence alignment of nucleocapsid protein from SARS-CoV-2, SARS-CoV, MERS and common cold viruses (OC43, HKU1, NL63, L229E) (Fig. 1). The peptides were additionally filtered to remove peptides having amino acids which could undergo any modifications. Peptides from the regions of nucleocapsid protein that were mutated in $>1 \%$ of sequenced cases in GISAID database were also excluded. In total, we selected three peptides as targets that could be reliably detected by mass spectrometry and were specific to SARS-CoV-2 as compared to other common coronaviruses. The selected peptides included ITFGGPSDSTGSNNQNGER, DGIIWVATEGALNTPK and NPANNAAIVLQLPQGTTLPK. Synthetic standards for these peptides were synthesized and characterized by vendor for the correct masses and were purified using high performance liquid chromatography. All the peptides were more than 95\% pure and peptide stock concentration was determined by amino acid analysis.

\section{Evaluation of selected anti-peptide antibodies}

Anti-peptide antibodies were generated for all the three selected peptides (SISCAPA Assay Technologies, Washington DC). As the nasopharyngeal swab samples were already tested for SARS-CoV-2 using RT-PCR-based molecular diagnostic testing, positive swab samples served as a positive control for evaluating the performance of the polyclonal antibodies 


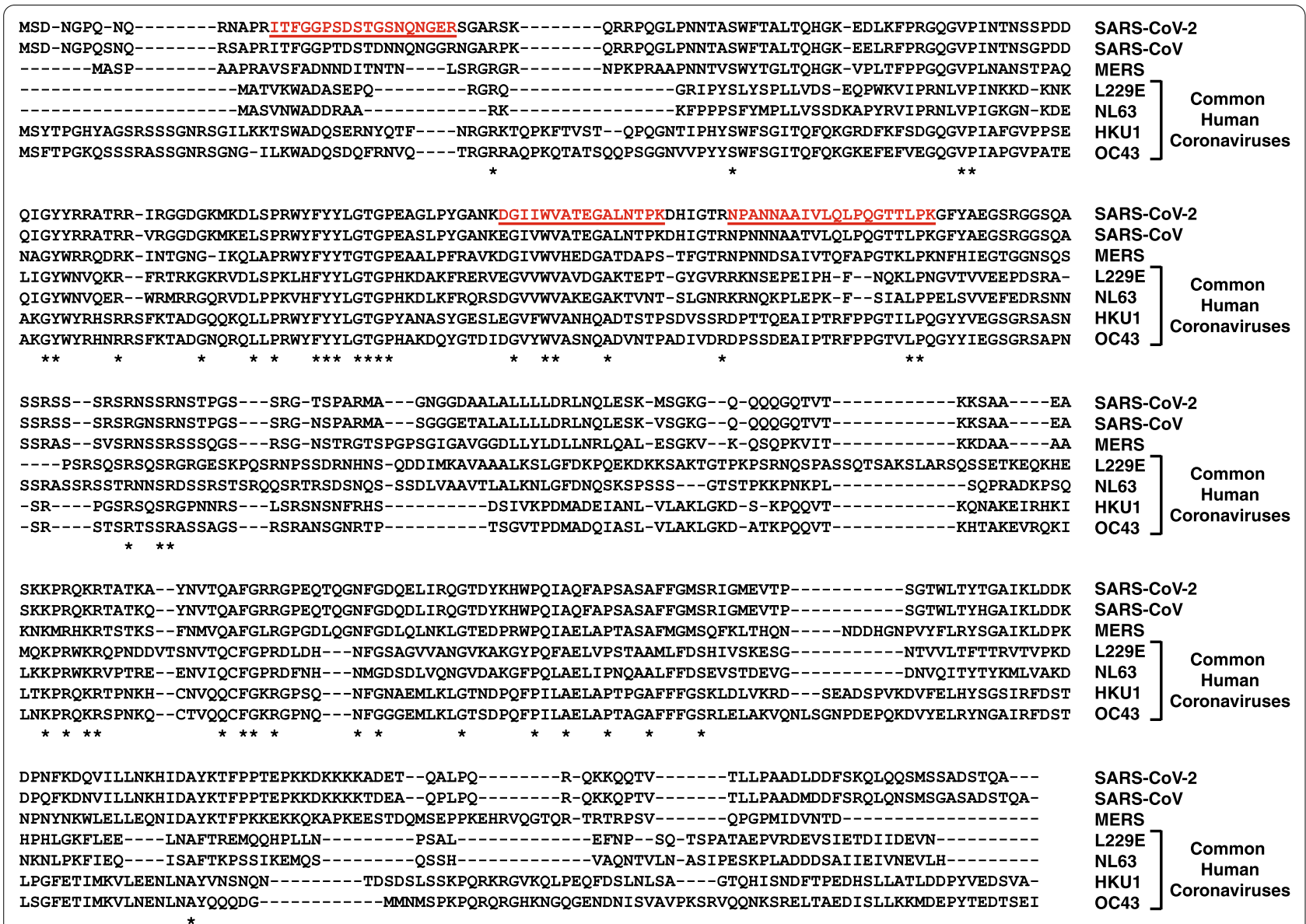

Fig. 1 Sequence alignment of SARS-CoV-2 nucleocapsid protein against related coronaviruses. The nucleocapsid protein sequence of SARS-CoV-2 virus was aligned with that of SARS-CoV, MERS and common human coronaviruses (L229E, NL63, HKU1 and OC43). The tryptic peptide sequences highlighted in red indicate the three proteotypic peptides selected for generation of anti-peptide antibodies as they are unique to SARS-CoV-2

and similarly negative swab samples were used as a negative control. Positive and negative samples were pooled separately and digested. The digests were then subjected for viral peptide enrichment on MSIA tips using Versette liquid handler platform. SISCAPAbased workflow employed for the detection of viral peptides is shown in Fig. 2. As expected, targeted analysis of the eluates from pooled negative swab samples did not show signal for any of the peptides analyzed, indicating high specificity of the enrichment and detection methods. In the pooled positive swab samples, we detected all the three peptides analyzed. These results indicate the feasibility of utilizing antipeptides antibodies to detect viral peptides with high specificity.

\section{Determining peptide calibration curves and repeatability}

To further characterize the sensitivity and reproducibility of the SISCAPA workflow, the limit of detection for the three peptides was determined by spiking different amounts of the synthetic light peptides $(0,50$ amol, 125 amol, 250 amol, 500 amol, $1 \mathrm{fmol}, 4 \mathrm{fmol}$, $20 \mathrm{fmol}, 100 \mathrm{fmol}$ ) in phosphate buffered saline, followed by enrichment and PRM analysis. The list of transitions and their areas for all singly charged $b$ and $y$ ions were exported from Skyline. The coefficient of variation $(\mathrm{CV})$ for each of the transitions was calculated for three replicates across all the dilutions and transitions with $C V<20$ were considered for further analysis. The transitions and $m / z$ considered for linear range and limit of detection (LOD) characterization are listed in Table 1 and Fig. 3A. All three peptides were detected at the lowest peptide amount injected i.e. $50 \mathrm{amol}$ and displayed excellent linearity at lower concentrations (Fig. 3B). The $\mathrm{CV}$ was $<20$ for all the three peptides analyzed. Next, we evaluated the reproducibility of the workflow by performing enrichment of peptides from the pooled SARS-CoV-2 positive nasopharyngeal swab digest in three different sets. In each experiment, three process replicates were 


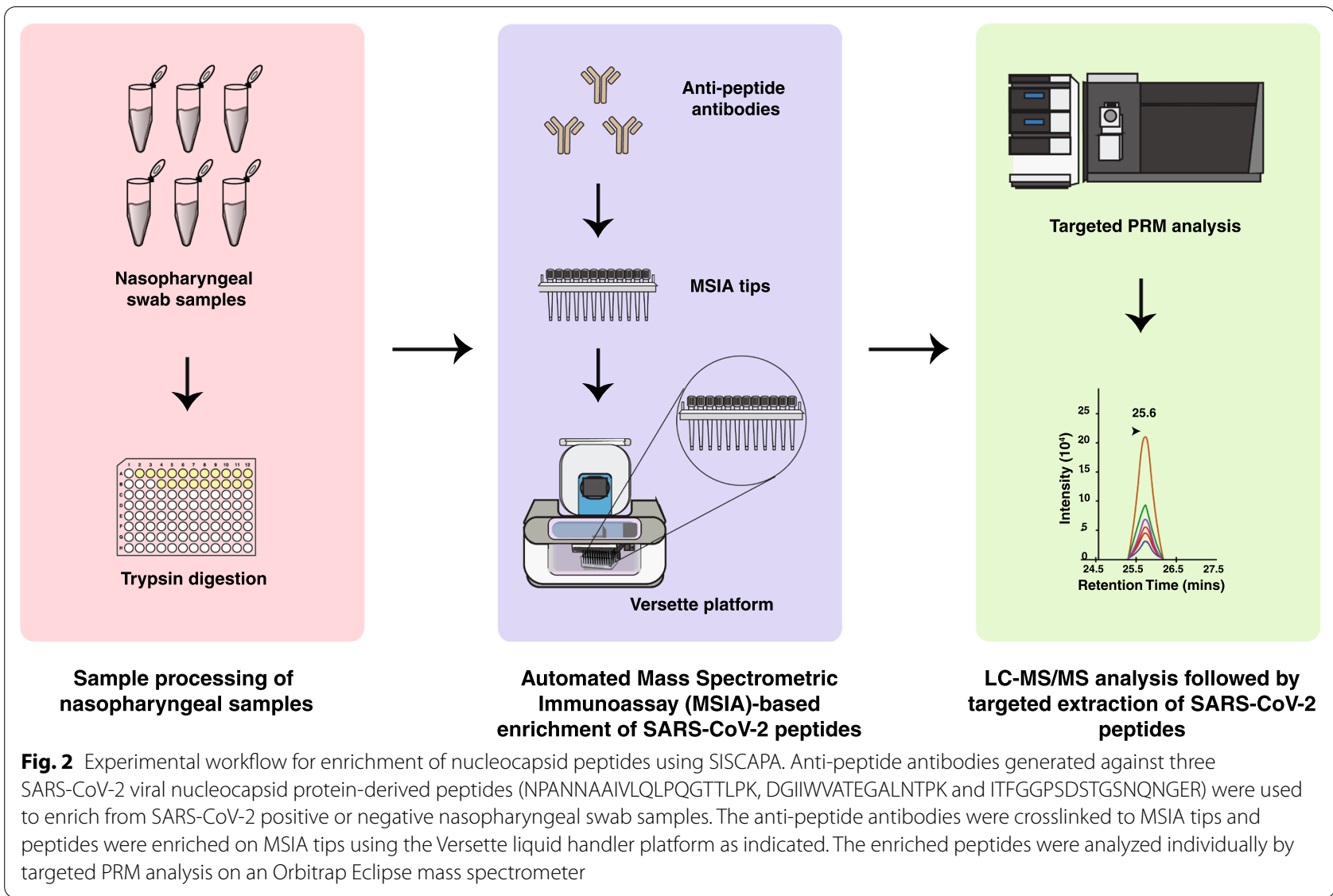

Table 1 Nucleocapsid protein-derived peptides selected for SISCAPA assays and their transitions

\begin{tabular}{lclll}
\hline Peptide & Position & $\mathbf{m} / \mathbf{z}$ & Charge & Selected transitions \\
\hline NPANNAAIVLQLPQGTTLPK & $150-169$ & 687.388 & 3 & $\mathrm{y} 10, \mathrm{y} 9, \mathrm{y} 8, \mathrm{y} 7, \mathrm{y} 6$ \\
DGIIWVATEGALNTPK & $128-143$ & 842.948 & 2 & $\mathrm{y} 12, \mathrm{y} 11, \mathrm{y} 10, \mathrm{y} 9, \mathrm{y} 7$ \\
ITFGGPSDSTGSNQNGER & $15-32$ & 912.411 & 2 & $\mathrm{y} 13, \mathrm{y} 11, \mathrm{y} 10, \mathrm{y} 9, \mathrm{y} 8$ \\
\hline
\end{tabular}

used to measure the inter and intra-experiment $\mathrm{CV}$. All the three peptides were reproducibly quantified with coefficient of variation of $<20$ in both within the experiment and between the experiments (Fig. 3C). (see Table 2). These results indicate that the analytical workflow demonstrated in this study for the detection of SARS-CoV-2 is highly reproducible and can be deployed for analyzing clinical specimens.

\section{Detection of SARS-CoV-2 viral antigens from nasopharyngeal swab samples}

Finally, we tested our approach on individual nasopharyngeal swab samples for viral detection. All the samples used in this study were tested for SARS-CoV-2 using routine RT-PCR diagnostic testing. Overall, we used 41 SARS-CoV-2 positive and 30 negative nasopharyngeal swab samples and performed enrichment of nucleocapsid peptides by anti-peptide antibodies using the workflow described in Fig. 2. The retention time for all the peptides was highly reproducible across the samples and we did not observe carryover in the negative samples. Overall, we did not detect PRM traces for the targeted peptides (ITFGGPSDSTGSNNQNGER, DGIIWVATEGALNTPK and NPANNAAIVLQLPQGTTLPK) in any of the 30 negative samples tested, indicating $100 \%$ specificity of the described workflow (Table 3). Among the RT-PCR positive samples tested for PRM analysis, samples were considered positive only if any two peptides were 


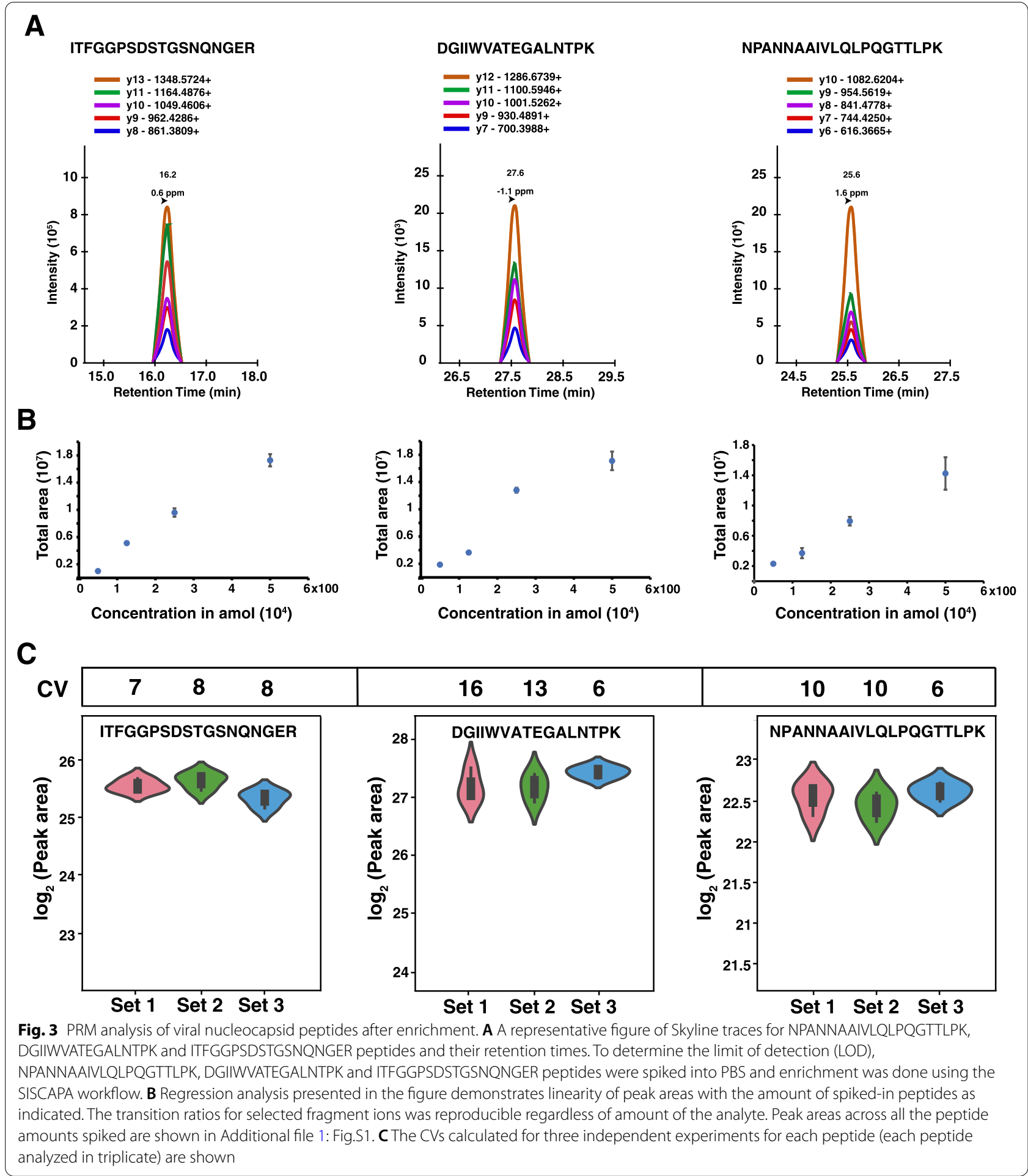

confidently identified with the expected transition ratios. Of the 41 samples, 38 samples were positive in PRM analysis with at least 2 peptides identified (all 3 peptides were identified in 30 samples).
Quantitatively, each peptide was positively correlated with $\mathrm{Ct}$ value of the respective samples with a Pearson correlation of 0.82 for ITFGGPSDSTGSNNQNGER peptide, 0.67 for DGIIWVATEGALNTPK peptide and 0.54 for NPANNAAIVLQLPQGTTLPK 
Table 2 Variability (reported as CV) for SISCAPA assay performed on 3 separate sets of pooled RT-PCR positive nasopharyngeal swab samples (Ct value <24). The total area was considered for calculating the mean and standard deviation

\begin{tabular}{llll}
\hline & DGIIWVATEGALNTPK & ITFGGPSDSTGSNQNGER & NPANNAAIVLQLPQGTTLPK \\
\hline Set 1 & & & $6.04 \mathrm{E}+06$ \\
Mean & $1.64 \mathrm{E}+08$ & $4.90 \mathrm{E}+07$ & $6.28 \mathrm{E}+05$ \\
SD & $2.63 \mathrm{E}+07$ & $3.37 \mathrm{E}+06$ & 10.38 \\
CV & 16.04 & 6.88 & $5.69 \mathrm{E}+06$ \\
Mean & $1.62 \mathrm{E}+08$ & $5.15 \mathrm{E}+07$ & $5.50 \mathrm{E}+05$ \\
Set 2 & & & 9.66 \\
SD & $2.13 \mathrm{E}+07$ & $4.30 \mathrm{E}+06$ & $6.27 \mathrm{E}+06$ \\
CV & 13.14 & 8.34 & $3.90 \mathrm{E}+05$ \\
Mean & $1.87 \mathrm{E}+08$ & $4.28 \mathrm{E}+07$ & 6.21 \\
Set 3 & $1.06 \mathrm{E}+07$ & & $3.60 \mathrm{E}+06$ \\
SD & 5.64 & 8.41 & \\
CV & & & \\
\hline
\end{tabular}

Table 3 Summary of MS-based detection of SARS-CoV-2 viral peptides from clinical nasopharyngeal swab samples using the SISCAPA workflow

\begin{tabular}{llll}
\hline & $\begin{array}{l}\text { Detection of SARS- } \\
\text { CoV-2 viral peptides by } \\
\text { SISCAPA approach }\end{array}$ & \\
\cline { 2 - 3 } & Positive & Negative & \\
\hline $\begin{array}{l}\text { SARS-CoV-2 positive } \\
\text { nasopharyngeal swab } \\
\text { samples ( } \mathrm{n}=41)\end{array}$ & 38 & 3 & Sensitivity-92.68\% \\
$\begin{array}{l}\text { SARS-CoV-2 negative } \\
\text { nasopharyngeal swab } \\
\text { samples }(\mathrm{n}=30)\end{array}$ & 30 & 0 & Specificity- 100\% \\
\hline
\end{tabular}

peptide (Fig. 4A). To further assess the quantitative precision of the correlation with the $\mathrm{Ct}$ value, we categorized all the positive samples into 4 groups based on their $\mathrm{Ct}$ value ranges (Ct 16-20, $20-22,22-26$ and $\mathrm{Ct}>26$ ) as shown in Fig. 4B. Of the three peptides, ITFGGPSDSTGSNNQNGER peptide showed the best quantitative performance across all the four groups of $\mathrm{Ct}$ values. This is a pilot study to show that SISCAPA-based enrichment of viral peptides could indeed detect viral peptides from nasopharyngeal swab samples and also has the potential to detect SARS-CoV-2 from other clinical samples such as urine [27]. Overall, we employed a semi-automated approach for the detection of the viral peptides where automated steps included samples preparation in 96-well plates and immunoaffinity purification using an automatic liquid handler.

\section{Conclusions}

In this study, we have demonstrated the applicability of anti-peptide antibodies for the enrichment of viral peptides from nasopharyngeal swab samples. This is the first study employing a SISCAPA approach for detection of novel SARS-CoV-2 in clinical samples. Using this approach, we found a specificity of $100 \%$ and sensitivity of $\sim 93 \%$ for detection of novel SARS $\mathrm{CoV}-2$ in clinically tested nasopharyngeal swab samples. Employing monoclonal anti-peptide antibodies could further achieve higher sensitivity of detection especially in the samples with higher $\mathrm{Ct}$ value (low viral load). Also, optimization of chromatographic conditions such as run time and flow rates could help improve the throughput without compromising the sensitivity of detection of SARS-CoV-2. An additional advantage of this approach is that it can be applied to detection of viral peptides in samples such as formalin-fixed paraffin-embedded (FFPE) sections where enrichment of viral proteins (as opposed to peptides) is impossible. 

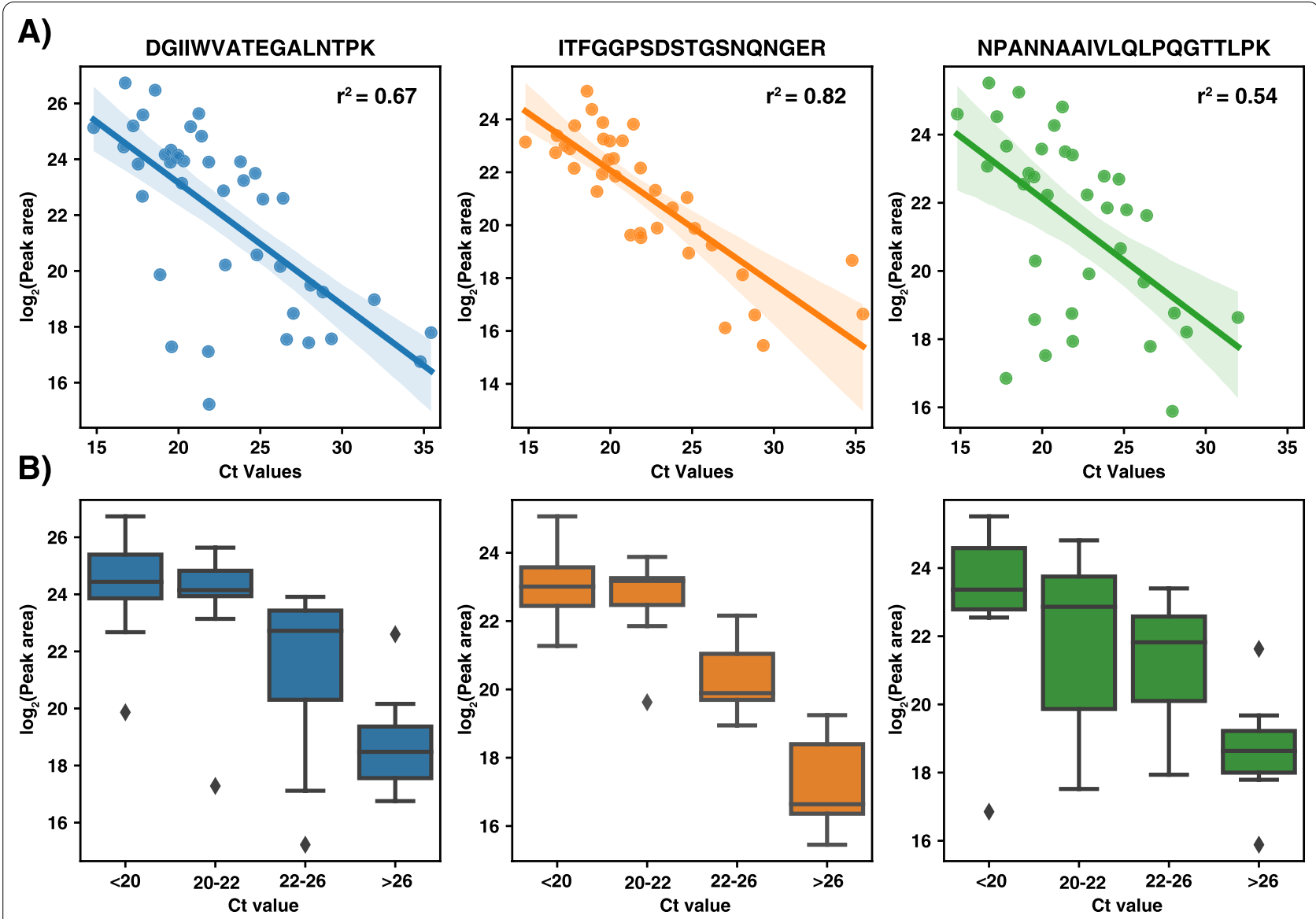

Fig. 4 Detection of SARS-CoV-2 viral antigens from clinical samples using SISCAPA workflow. A 41 nasopharyngeal swab samples that were positive for SARS-CoV-2 using RT-PCR testing were processed using the workflow described in this study. The cumulative peak areas for all the three peptides are plotted against the Ct values reported by the RT-PCR testing. B Box plots of peak areas for each peptide are plotted across different groups based on the Ct values (Ct values $<20,20-22,22-26$ and $>26$ ) of the SARS-CoV-2 positive samples as indicated

\section{Abbreviations}

RT-PCR: Reverse transcriptase-polymerase chain reaction; SISCAPA: Stable Isotope Standards and Capture by Anti-Peptide Antibodies; PRM: Parallel reaction monitoring; NP swab: Nasopharyngeal swab; MSIA: Mass spectrometric immunoassay; LOD: Limit of detection.

\section{Supplementary Information}

The online version contains supplementary material available at https://doi. org/10.1186/s12014-021-09331-z.

Additional file 1: Figure S1. Figure showing the correlation of peak areas across the entire range of synthetic peptide amounts spiked in phosphate buffered saline followed by enrichment and targeted analysis.

\section{Acknowledgements}

Not applicable.

\section{Authors' contributions}

AP, SKG, RJS, BRK, SC and KKM designed the study. SC and KKM performed the experiments and analysis. SR, PMV, TDM, JK assisted with the experiments and analysis. AKM, SC, KKM prepared the figures. KKM and SC wrote the manuscript, AP and TDM critically edited the manuscript. All authors read and approved the manuscript.

\section{Funding}

This study was supported by DBT/Wellcome Trust India Alliance Margdarshi Fellowship grant IA/M/15/1/502023 awarded to AP and the generosity of Eric and Wendy Schmidt

\section{Availability of data and materials}

The datasets generated during the current study are available under PRIDE repository with accession number PXD028505.

\section{Declarations}

Ethics approval and consent to participate

All the samples were collected after prior approval from Mayo Clinic's Institutional Review Board.

\section{Consent for publication}

Not applicable. 


\section{Competing interests}

The authors declare that they have no competing interests.

\section{Author details}

'Department of Laboratory Medicine and Pathology, Division of Clinical Biochemistry and Immunology, Mayo Clinic, Rochester, MN 55905, USA. ${ }^{2}$ Manipal Academy of Higher Education, Manipal 576104, Karnataka, India. ${ }^{3}$ Institute of Bioinformatics, International Technology Park, Bangalore 560066, Karnataka, India. ${ }^{4}$ Center for Molecular Medicine, National Institute of Mental Health and Neurosciences, Hosur Road, Bangalore 560029, Karnataka, India. ${ }^{5}$ Center for Individualized Medicine, Mayo Clinic, Rochester, MN 55905, USA. ${ }^{6}$ Department of Laboratory Medicine and Pathology, Division of Laboratory Genetics and Genomics, Mayo Clinic, Rochester, MN 55905, USA. ${ }^{7}$ Department of Medicine, Division of Endocrinology, Mayo Clinic, Rochester, MN 55902, USA.

Received: 9 June 2021 Accepted: 1 October 2021

Published online: 22 October 2021

\section{References}

1. Wang C, et al. A novel coronavirus outbreak of global health concern. Lancet. 2020;395(10223):470-3.

2. Udugama B, et al. Diagnosing COVID-19: the disease and tools for detection. ACS Nano. 2020;14(4):3822-35.

3. Esbin MN, et al. Overcoming the bottleneck to widespread testing: a rapid review of nucleic acid testing approaches for COVID-19 detection. RNA. 2020;26(7):771-83.

4. Guglielmi G. The explosion of new coronavirus tests that could help to end the pandemic. Nature. 2020;583(7817):506-9.

5. Garg U, Zhang YV. Mass spectrometry in clinical laboratory: applications in biomolecular analysis. Methods Mol Biol. 2016;1378:1-9.

6. Aebersold R, Picotti P. Method of the year 2012. Nat Methods. 2013;10(1):1.

7. Cardozo KHM, et al. Establishing a mass spectrometry-based system for rapid detection of SARS-CoV-2 in large clinical sample cohorts. Nat Commun. 2020;11(1):6201.

8. Nachtigall FM, et al. Detection of SARS-CoV-2 in nasal swabs using MALDI-MS. Nat Biotechnol. 2020;38(10):1168-73.

9. Nikolaev EN, et al. Mass-spectrometric detection of SARS-CoV-2 virus in scrapings of the epithelium of the nasopharynx of infected patients via nucleocapsid N protein. J Proteome Res. 2020;19(11):4393-7.

10. Dollman NL, Griffin JH, Downard KM. Detection, mapping, and proteotyping of SARS-CoV-2 coronavirus with high resolution mass spectrometry. ACS Infect Dis. 2020;6(12):3269-76.

11. Ihling C, et al. Mass spectrometric identification of SARS-CoV-2 proteins from gargle solution samples of COVID-19 patients. J Proteome Res. 2020;19(11):4389-92.

12. Singh $P$, et al. A rapid and sensitive method to detect SARS-CoV-2 virus using targeted-mass spectrometry. J Proteins Proteom. 2020. https://doi. org/10.1007/s42485-020-00044-9.
13. Wandernoth $P$, et al. Detection of severe acute respiratory syndrome coronavirus 2 (SARS-CoV-2) by mass spectrometry. Viruses. 2020. https:// doi.org/10.3390/v12080849.

14. Renuse $\mathrm{S}$, et al. A mass spectrometry-based targeted assay for detection of SARS-CoV-2 antigen from clinical specimens. EBioMedicine. 2021;69:103465.

15. Anderson NL, et al. Mass spectrometric quantitation of peptides and proteins using Stable Isotope Standards and Capture by Anti-Peptide Antibodies (SISCAPA). J Proteome Res. 2004;3(2):235-44.

16. Katafuchi T, et al. Detection of FGF15 in plasma by stable isotope standards and capture by anti-peptide antibodies and targeted mass spectrometry. Cell Metab. 2015;21(6):898-904.

17. Xu Q, et al. Quantitative assessment of human serum transferrin receptor in breast cancer patients pre- and post-chemotherapy using peptide immunoaffinity enrichment coupled with targeted proteomics. Clin Chim Acta. 2015:448:118-23.

18. Collins CJ, et al. Rapid multiplexed proteomic screening for primary immunodeficiency disorders from dried blood spots. Front Immunol. 2018;9:2756.

19. Hsiao YC, et al. Development of a multiplexed assay for oral cancer candidate biomarkers using peptide immunoaffinity enrichment and targeted mass spectrometry. Mol Cell Proteomics. 2017;16(10):1829-49.

20. Kuhn E, et al. Interlaboratory evaluation of automated, multiplexed peptide immunoaffinity enrichment coupled to multiple reaction monitoring mass spectrometry for quantifying proteins in plasma. Mol Cell Proteomics. 2012;11(6):M111.013854.

21. Schoenherr RM, et al. Quantification of estrogen receptor, progesterone receptor, and human epidermal growth factor receptor 2 protein expression in bone biopsies by targeted mass spectrometry without acid decalcification. Clin Chem. 2020;66(11):1459-61.

22. Zheng $\mathrm{N}$, et al. Antipeptide immunocapture with in-sample Calibration curve strategy for sensitive and robust LC-MS/MS bioanalysis of clinical protein biomarkers in formalin-fixed paraffin-embedded tumor tissues. Anal Chem. 2020;92(21):14713-22.

23. Sievers F, et al. Fast, scalable generation of high-quality protein multiple sequence alignments using Clustal Omega. Mol Syst Biol. 2011;7:539.

24. Fang S, et al. GESS: a database of global evaluation of SARS-CoV-2/hCoV19 sequences. Nucleic Acids Res. 2021:49(D1):D706-14.

25. Hoofnagle AN, et al. Recommendations for the generation, quantification, storage, and handling of peptides used for mass spectrometrybased assays. Clin Chem. 2016;62(1):48-69.

26. MacLean B, et al. Skyline: an open source document editor for creating and analyzing targeted proteomics experiments. Bioinformatics. 2010;26(7):966-8.

27. Chavan S, et al. Mass spectrometric analysis of urine from COVID-19 patients for detection of SARS-CoV-2 viral antigen and to study host response. J Proteome Res. 2021;20(7):3404-13.

\section{Publisher's Note}

Springer Nature remains neutral with regard to jurisdictional claims in published maps and institutional affiliations.
Ready to submit your research? Choose BMC and benefit from:

- fast, convenient online submission

- thorough peer review by experienced researchers in your field

- rapid publication on acceptance

- support for research data, including large and complex data types

- gold Open Access which fosters wider collaboration and increased citations

- maximum visibility for your research: over 100M website views per year

At $\mathrm{BMC}$, research is always in progress.

Learn more biomedcentral.com/submissions 